\title{
Saberes docentes e formação inicial de professores: implicações e desafios para as propostas de formação
}

\author{
Patrícia Cristina Albieri de Almeida \\ Pontifícia Universidade Católica/SP \\ Jefferson Biajone \\ Escola Preparatória de Cadetes do Exército
}

\section{Resumo}

Trata-se de um estudo que teve por objetivo discutir as implicações e repercussões das pesquisas acerca do knowlwdge base para a formação inicial de professores. Esse campo de pesquisa surge em âmbito internacional na década de 1980 e vem apresentando expressiva profusão e multiplicação dos estudos na área. A importância desses estudos é atribuída, em grande parte, ao seu potencial no desenvolvimento de ações formativas que vão além de uma abordagem acadêmica, envolvendo as dimensões pessoal, profissional e organizacional da profissão docente. Foram analisadas obras de autores de referência na área como Tardif, Gauthier e Shulman. A análise das produções deu-se a partir de dois enfoques: primeiro, buscou-se apreender como definem saberes docentes numa perspectiva conceitual e tipológica e, depois, identificou-se indícios de alternativas de natureza teórica e prática para a formação inicial de professores. 0 estudo revela que a elaboração de um repertório de conhecimentos para o ensino, tendo como referência os saberes profissionais dos professores tais como estes os mobilizam e utilizam em diversos contextos do trabalho cotidiano, permite a introdução de dispositivos de formação que visem habituar os futuros educadores à prática profissional. Destaca-se a necessidade de garantir que as formações cultural, científica, pedagógica e disciplinar estejam vinculadas à formação prática, consolidando, assim, uma Teoria do Ensino.

\section{Palavras-chave}

Saberes docentes - Formação de professores - Projetos de formação.

\footnotetext{
Correspndência:

Patrícia Cristina Albieri de Almeida

Rua Polônia, 384 Jd. das Nações

12030-206 - Taubaté - SP

e-mail: patricia.aa@uol.com.br
} 


\title{
Teaching knowledges and initial teacher education: implications and challenges to proposals of formation
}

\author{
Patrícia Cristina Albieri de Almeida \\ Pontifícia Universidade Católica/SP \\ Jefferson Biajone \\ Escola Preparatória de Cadetes do Exército
}

\begin{abstract}
This work had as its objective to discuss the implications and repercussions of the studies about Knowledge Base upon the initial education of teachers. This field of research emerged internationally in the 1980s, and has been showing signs of significant diffusion and expansion. The importance of the studies on this topic is attributed largely to their potential in the development of formative actions that go beyond the academic approach, to involve the personal, professional, and organizational dimensions of the teaching profession. The study analyzes the works of major authors in this field, such as Tardif, Gauthier, and Schulman. The analysis of this production was made from two viewpoints: first, it tried to apprehend how teaching knowledges are defined under a conceptual and typological perspective, and then it hinted at alternatives of theoretical and practical natures to teacher initial education. The study reveals that the creation of a repertoire of knowledges for teaching, having as its reference the professional knowledges of the teachers as mobilized and employed by them in their various daily work contexts allows the introduction of formation devices aiming at habituating the future educators to professional practice. It highlights the need of ensuring that the cultural, scientific, pedagogical, and disciplinary formations are linked to the practical formation, thereby consolidating a Theory of Teaching.
\end{abstract}

\section{Keywords}

Teacher knowledges - Teacher education - Teacher education projects.

\footnotetext{
Contact:

Patrícia Cristina Albieri de Almeida Rua Polônia, 384 Jd. das Nações 12030-206 - Taubaté - SP e-mail: patricia.aa@uol.com.br
} 
Estados Unidos e Canadá iniciaram, no final dos anos 1980, um movimento reformista na formação inicial de professores da Educação Básica. As reformas decorrentes desse movimento tinham por objetivo a reivindicação de status profissional para os profissionais da Educação. Apoiados na premissa de que existe uma base de conhecimento 1 para o ensino, muitos pesquisadores foram mobilizados a investigar e sistematizar esses saberes. Buscaram compreender a genealogia da atividade docente e, assim, convalidar um corpus de saberes mobilizados pelo professor com a intenção de melhorar a formação de professores. Buscaram, também, iniciar um processo de profissionalização que favorecesse a legitimidade da profissão e, dessa forma, transpusesse a concepção da docência ligada a um fazer vocacionado.

Compartilhava-se, desse modo, a crença de que a base de conhecimento permitiria estruturar a educação do professor e instruiria diretamente as práticas de formação. As reformas na América do Norte influenciaram posteriormente vários países europeus e anglo-saxões e estenderam-se à América Latina.

Borges e Tardif (2001) apontam diferenças e variações significativas entre os países que vivenciaram ou estão vivenciando essas reformas. No entanto, identificam, com base em Tardif, Lessard e Gauthier (2001), objetivos e princípios comuns às reformas como: conceber o ensino como uma atividade profissional que se apóia num sólido repertório de conhecimentos; considerar os professores como práticos reflexivos; ver a prática profissional como um lugar de formação e de produção de saberes pelos práticos; instaurar normas de acesso à profissão e estabelecer ligação entre as instituições universitárias de formação e as escolas da Educação Básica.

0 knowledge base como campo de pesquisa surge em âmbito internacional na década de 1980, e vem apresentando expressiva profusão e multiplicação dos estudos na área. Borges e Tardif (2001), na apresentação do dossiê temático - Os saberes docentes e sua formação - da Revista Educação \& Sociedade, relatam a existência de 144 referências em relação às palavras teacher e knowledge na base de dados ERIC de 1966, ano esse em que ela iniciou suas atividades. Já em 1996, as 144 referências iniciais saltaram para 989 , o que demonstrou ser um aumento de $700 \%$ nas produções sobre os saberes docentes. Ainda que expressivo, esse número não contempla a produção em outras línguas, cuja existência não é catalogada pela referida base de dados.

Segundo os autores, o crescimento substancial das pesquisas é quantitativo e qualitativo, tanto no que diz respeito aos enfoques e às metodologias utilizados, quanto em relação às disciplinas e aos quadros teóricos adotados. A essa produção, é possível acrescentar inúmeros trabalhos que abordam temáticas próximas ao saber docente, as quais podem ser categorizadas como crenças, concepções, competências, pensamento do professor, suas representações, entre outros. Um dos aspectos que caracterizam os estudos sobre a constituição do trabalho docente é a valorização dos diferentes aspectos da história individual e profissional do docente, utilizando uma abordagem teórico-metodológica que dá voz ao professor, sendo compreendido como um profissional que adquire e desenvolve conhecimentos, a partir da prática e no confronto com as condições da profissão.

É nessa perspectiva que as produções a respeito da temática saberes docentes têm ocupado papel de destaque na formação de professores, o que é atribuído, em grande parte, ao seu potencial no desenvolvimento de ações formativas que vão além de uma abordagem acadêmica, envolvendo as dimensões pessoal, profissional e organizacional da profissão docente.

Assim, considerando que as pesquisas acerca do knowledge base tem como finalidade identificar um repertório de conhecimentos do ensino que serviriam para a elaboração de programas de formação de professores, a nos-

1. Segundo Shulman (2004), em ensino, knowledge base (base de conhecimento) é o corpo de compreensões, conhecimentos, habilidades e disposições de que um professor necessita para atuar efetivamente numa dada situação de ensino. 
sa intenção é discutir as implicações e repercussões dessas pesquisas para a formação inicial de professores.

Analisamos algumas das obras de autores de referência na área como Tardif (2002), Gauthier (1998), Shulman (1986; 2004), e algumas das produções que têm como foco de discussão os saberes docentes.

É importante esclarecer que, no Brasil, a introdução dessa temática deu-se, especialmente, pelas obras de Tardif e, posteriormente, de Gauthier e Shulman. No entanto, o tema saber docente vem sendo direta e indiretamente tratado por autores como Philippe Perrenoud, Antônio Nóvoa e Keneth Zeichner.

As produções referentes ao saberes docentes foram analisadas a partir de dois enfoques: primeiro, buscamos apreender como definem saberes docentes numa perspectiva conceitual e tipológica e, depois, procuramos indícios de alternativas de natureza teórica e prática para a formação inicial de professores com base nos saberes docentes.

\section{Saberes docentes: concepções e tipologias}

Como destacamos na introdução, dado ao número expressivo de produções a respeito do knowledge base a partir de concepções e orientações variadas, observa-se uma diversidade conceitual e metodológica das pesquisas. Neste texto, apresentaremos apenas as concepções e tipologias sobre os saberes da docência na perspectiva de três autores: Gauthier, Tardif e Shulman. Nossa intenção é pôr em evidência as contribuições dessas pesquisas para a formação inicial de professores, sem a pretensão de explorar exaustivamente as diferentes tipologias e classificações desse campo de pesquisa.

Iniciaremos com as contribuições de Gauthier e colaboradores (1998), que realizaram estudos das pesquisas sobre o ensino no intuito de identificar convergências em relação aos saberes mobilizados na ação pedagógica e com o objetivo de examinar as implicações, for- mular problemáticas, avaliar resultados e esboçar uma teoria geral da pedagogia.

0 autor usa a sentença "conhece-te a ti mesmo", do oráculo de Delfos, para dizer que ainda se sabe muito pouco a respeito dos fenômenos que são inerentes ao ensino. Argumenta que ao "contrário de outros ofícios que desenvolveram um corpus de saberes, o ensino tarda a refletir sobre si mesmo" (Gauthier, 1998, p. 20). Segundo o autor, avançar na pesquisa de um repertório de conhecimentos sobre o ensino possibilita-nos enfrentar dois obstáculos que historicamente se interpuseram à pedagogia: de um ofício sem saberes e de saberes sem ofício.

0 primeiro diz respeito à própria atividade docente que é exercida sem revelar os saberes que the são inerentes. Explica que, apesar de o ensino ser uma atividade que se realiza desde a antiguidade, ainda se sabe muito pouco a seu respeito, e que convivemos com certas idéias preconcebidas que contribuem para o "enorme erro de manter o ensino numa cegueira conceitual" (Gauthier, 1998, p. 20). Idéias que defendem, por exemplo, que ensinar consiste apenas em transmitir conhecimentos, bastando, portanto, conhecer o conteúdo objeto de ensino ou que é uma questão de talento, bom senso, intuição ou, ainda, que basta ter experiência e cultura.

Os saberes referentes ao conteúdo, à experiência e à cultura são essenciais no exercício da atividade docente, mas "tomá-los como exclusivos é mais uma vez contribuir para manter o ensino na ignorância" (Gauthier, 1998, p. 25) e reforçar a perpetuação de um ofício sem saberes.

0 segundo obstáculo diz respeito aos saberes sem ofício, que têm sua origem nas Ciências da Educação, ou seja, são os conhecimentos produzidos nos centros acadêmicos. Muitos desses conhecimentos, segundo Gauthier (1998), foram produzidos sem considerar as condições concretas do exercício do magistério. São saberes que não se dirigiram ao professor real, cuja atuação se dá numa sala de aula concreta onde estão presentes muitas variáveis 
que interferem no processo de ensino e exigem tomadas de decisão, ou seja, “[...] buscou-se formalizar o ensino reduzindo de tal modo a sua complexidade que ele não mais encontra correspondente na realidade" (p. 25). Para o autor, esse obstáculo contribuiu para a desprofissionalização da atividade docente

[...] ao reforçar nos professores a idéia de que a pesquisa universitária não lhes podia fornecer nada de realmente útil, e que, conseqüentemente, era muito mais pertinente que uns continuassem se apoiando na experiência pessoal, outros na intuição, outros no bom senso etc. (p. 27)

Para Gauthier (1998), o desafio da profissionalização docente é evitar esses dois erros: ofício sem saberes e saberes sem ofício. Ao admitir que as pesquisas já revelam a presença de um repertório de conhecimentos próprios ao ensino, propõe um ofício feito de saberes. Em seu livro Por uma teoria da Pedagogia, concebe o ensino como a mobilização de vários saberes que formam uma espécie de reservatório que é utilizado para responder às exigências das situações concretas de ensino. Do ponto de vista tipológico, o autor classifica os saberes em: disciplinar, referente ao conhecimento do conteúdo a ser ensinado; curricular, relativo à transformação da disciplina em programa de ensino; Ciências da Educação, relacionado ao saber profissional específico que não está diretamente relacionado com a ação pedagógica; tradição pedagógica, relativo ao saber de dar aulas que será adaptado e modificado pelo saber experiencial, podendo ser validado pelo saber da ação pedagógica; experiência, referente aos julgamentos privados responsáveis pela elaboração, ao longo do tempo, de uma jurisprudência particular; ação pedagógica, referente ao saber experiencial tornado público e testado.

Para o autor, reconhecer a existência de um repertório de conhecimentos reflete um olhar ressignificado para o professor, que passa a ser visto como um
[...] profissional, ou seja, como aquele que, munido de saberes e confrontando a uma situação complexa que resiste à simples aplicação dos saberes para resolver a situação, deve deliberar, julgar e decidir com relação à ação a ser adotada, ao gesto a ser feito ou à palavra a ser pronunciada antes, durante e após o ato pedagógico. (Gauthier, 1998, p. 331)

Outro autor que analisa a questão dos saberes profissionais e a sua relação na problemática da profissionalização do ensino e da formação de professores é Maurice Tardif. A primeira produção desse autor publicada no Brasil ocorreu em 1991, por meio de um artigo na Revista Teoria \& Educação, em parceria com Lessard e Lahaye. 0 artigo apresenta considerações gerais sobre a situação dos docentes em relação aos saberes, buscando identificar e definir os diferentes saberes presentes na prática docente, bem como as relações estabelecidas entre eles e os professores.

Em 2002, foi lançado o livro Saberes docentes e formação profissional, que reúne oito ensaios de Tardif publicados desde 1991. Esses ensaios representam diferentes momentos e etapas de um itinerário de pesquisa e de reflexão do autor. É importante salientar que ele situa o saber do professor a partir de seis fios condutores. 0 primeiro diz respeito ao saber e trabalho - o saber do professor deve ser compreendido em íntima relação com o trabalho na escola e na sala de aula: são as relações mediadas pelo trabalho que fornecem princípios para enfrentar e solucionar situações cotidianas. 0 segundo fio condutor é a diversidade $d o$ saber, pois entende que o saber dos professores é plural, compósito, heterogêneo, por envolver, no próprio exercício da ação docente, conhecimentos e um saber-fazer bastante variados e, normalmente, de natureza diferente. 0 terceiro é a temporalidade do saber - no qual reconhece o saber dos professores como temporal, uma vez que o saber é adquirido no contexto de uma história de vida e de uma 
carreira profissional. 0 quarto, denominado como a experiência de trabalho enquanto fundamento do saber, focaliza os saberes oriundos da experiência do trabalho cotidiano como alicerce da prática e da competência profissionais. É no contexto em que ocorre o ensino que o docente desenvolve o habitus, que são certas disposições adquiridas na e pela prática real. 0 quinto, saberes humanos a respeito de saberes humanos, expressa a idéia de trabalho interativo, um trabalho em que o trabalhador se relaciona com o seu objeto de trabalho fundamentalmente por meio da interação humana. 0 sexto e último, saberes e formação profissional, é decorrente dos anteriores, ou seja, expressa a necessidade de repensar a formação para o magistério, considerando os saberes dos professores e as realidades específicas de seu trabalho cotidiano.

Para Tardif (2002), a relação dos docentes com os saberes não é restrita a uma função de transmissão de conhecimentos já constituidos. Ele explica que a prática docente integra diferentes saberes e que mantém diferentes relações com eles. Define o saber docente “[...] como um saber plural, formado pelo amálgama, mais ou menos coerente, de saberes oriundos da formação profissional e de saberes disciplinares, curriculares e experienciais” (p. 36). Nessa perspectiva, os saberes profissionais dos professores são temporais, plurais e heterogêneos, personalizados e situados, e carregam as marcas do ser humano.

Nos ensaios do Tardif (2002), observa-se uma valorização da pluralidade e a heterogeneidade do saber docente, destacando-se a importância dos saberes da experiência. Também apresentam algumas características dos saberes profissionais segundo a definição de epistemologia da prática profissional dos professores, compreendida como o estudo do conjunto dos saberes utilizados realmente pelos profissionais em seu espaço de trabalho cotidiano para desempenhar todas as suas tarefas.

Considerando que esses saberes são provenientes de diferentes fontes e que os professores estabelecem diferentes relações com eles, tipologicamente Tardif (2002) os classifica em: saberes da formação profissional (das ciências da educação e da ideologia pedagógica), compreendido como o conjunto de saberes transmitidos pelas instituições de formação de professores; saberes disciplinares, correspondentes aos diversos campos do conhecimento sob a forma de disciplina - são saberes sociais definidos e selecionados pela instituição universitária e incorporados na prática docente; saberes curriculares, que correspondem aos discursos, objetivos, conteúdos e métodos a partir dos quais a instituição escolar categoriza e apresenta os saberes sociais por ela definidos e selecionados como modelos da cultura erudita e de formação para a cultura erudita; e por fim, saberes experienciais, que são aqueles saberes que brotam da experiência e são por ela validados, incorporando a experiência individual e coletiva sob a forma de habitus e de habilidades, de saber-fazer e de saber-ser.

Para o autor, as múltiplas articulações entre a prática docente e os saberes fazem dos professores um grupo social e profissional que, para existir, precisa dominar, integrar e mobilizar tais saberes, o que é condição sine qua non para a prática.

Em 2005, Tardif e Lessard publicaram o livro $O$ trabalho docente: elementos para uma teoria da docência como profissão de interações humanas. Trata-se de uma obra que tem como objeto de investigação o trabalho docente no cotidiano escolar com a intenção de descrever, analisar e compreender tal como é desenvolvido pelos professores. 0 estudo se fundamenta em entrevistas realizadas com professores, diretores de escolas, funcionários, orientadores pedagógicos etc. e observações nas classes e no ambiente das escolas em diferentes momentos do ano escolar.

A docência é compreendida, por Tardif e Lessard (2005), como "[...] uma forma particular de trabalho sobre o humano, ou seja, uma atividade em que o trabalhador se dedica ao seu 'objeto' de trabalho, que é justamente um outro ser humano, no modo fundamental da interação humana”. Os autores colocam em 
evidência “[...] as condições, as tensões e os dilemas que fazem parte desse trabalho feito sobre e com outrem, bem como a vivência das pessoas que o realizam diariamente" (p. 8), pois entendem que é na ação e na interação dos atores escolares que se estrutura a organização do trabalho na escola.

Outro autor que tem contribuído para o progressivo fortalecimento do campo educacional dos saberes docentes é Lee Shulman que, como pesquisador do programa knowledge base, tem sido referência para as reformas educativas, não somente norte-americanas, mas também estrangeiras, dada a influência de seus trabalhos nas pesquisas e nas políticas de outros países.

Ao debruçar-se sobre o knowledge base, Shulman (1986) revela que a essência dos programas de formação nas reformas educacionais e dos programas de avaliação e certificação de professores consistia tão somente agrupar habilidades, conhecimentos disciplinares e pedagógicos necessários à realização das atribuições docentes num determinado contexto de ensino. Para o autor, a ênfase das pesquisas que têm servido de referência para os programas de formação e certificação docente é em como os professores administram suas classes, organizam as atividades, alocam tempos e turnos, estruturam tarefas, fazem críticas e elogios, formulam os níveis de suas questões, planejam lições e julgam o entendimento geral dos estudantes. Shulman (2004) demonstra que os resultados das pesquisas sobre o ensino eficiente, embora valiosos, não são a única fonte de evidência para fundamentar uma definição sobre a base de conhecimento no ensino. Há um ponto cego com relação ao conteúdo que caracteriza essas pesquisas, denominado pelo autor de paradigma ausente, ou seja, perdem-se questões sobre o conteúdo das lições ensinadas, as questões feitas e as explicações oferecidas.

Acreditando que essas pesquisas trivializam a prática pedagógica, ignorando assim sua complexidade e reduzindo suas demandas, Shulman opta por contribuir e consolidar a corrente do knowledge base ao desenvolver seu próprio pro- grama de pesquisas, tendo como foco as seguintes questões: Qual conhecimento da matéria ensinada os professores têm em sua mente? Quais são as fontes dos conhecimentos dos professores? 0 que um professor sabe e quando ele ou ela vem a saber disso? Como um novo conhecimento é adquirido, o velho conhecimento é revisto e ambos, combinados, formam uma base de conhecimentos?

Shulman e seus colaboradores dedicam-se, então, a investigar a mobilização dos saberes passíveis de ensino sob uma perspectiva compreensiva dos conhecimentos e das ações dos professores, agora vistos como sujeitos dessas ações, sujeitos estes com história de vida pessoal e profissional, produtores e mobilizadores de saberes no exercício de sua prática; plenos de concepções sobre o mundo que os cerca: seus alunos, os conteúdos que ensinam, os currículos que seguem etc.

Shulman (1986) distingue três categorias de conhecimentos presentes no desenvolvimento cognitivo do professor: subject knowledge matter (conhecimento do conteúdo da matéria ensinada); pedagogical knowledge matter (conhecimento pedagógico da matéria) e curricular knowledge (conhecimento curricular). Outros de seus posteriores trabalhos, segundo Sztajn (2002), contemplaram uma revisão das três categorias mencionadas, ora propondo novas, ora eliminando outras, mas por fim mantendo as propostas originárias de seu trabalho de 1986, as quais apresentamos a seguir.

0 subject knowledge matter refere-se às compreensões do professor acerca da estrutura da disciplina, de como ele organiza cognitivamente o conhecimento da matéria que será objeto de ensino. Essa compreensão requer ir além dos fatos e conceitos intrínsecos à disciplina e pressupõe o conhecimento das formas pelas quais os princípios fundamentais de uma área do conhecimento estão organizados. Assim, o domínio da estrutura da disciplina não se resume tão somente à detenção bruta dos fatos e conceitos do conteúdo, mas também à compreensão dos processos de sua produção, representação e validação epistemológica, o que 
requer entender a estrutura da disciplina compreendendo o domínio atitudinal, conceitual, procedimental, representacional e validativo do conteúdo.

Para Shulman (1986), o professor:

\section{[...] needs not only understand that something} is so; the teacher must further understand why it is so, on what grounds its warrant can be asserted, and under what circumstances our belief in its justification can be weakened and even denied. Moreover, we expect the teacher to understand why a given topic is particularly central to a discipline whereas another may be somewhat peripheral. (p. 9) ${ }^{2}$

Assim, para Shulman (2004), a primeira fonte do knowledge base é o conhecimento do conteúdo que será objeto de ensino. Esse conhecimento repousa em dois fundamentos: a literatura acumulada na área e o conhecimento filosófico e histórico sobre a natureza do conhecimento no campo de estudo. 0 autor explica que o professor tem responsabilidades especiais em relação ao conhecimento do conteúdo, servindo como fonte primária do entendimento do aluno com a relação à disciplina. Isso significa que o modo pelo qual esse entendimento é comunicado leva ao aluno o que é essencial sobre um assunto e o que é periférico. Ao enfrentar a diversidade dos alunos, o professor deve ter a flexibilidade e a compreensão multifacetada, adequada para conceber explicações alternativas dos mesmos conceitos e princípios.

Já o pedagogical knowledge matter consiste nos modos de formular e apresentar o conteúdo de forma a torná-lo compreensível aos alunos, incluindo analogias, ilustrações, exemplos, explanações e demonstrações. A ênfase está nas maneiras de se representar e reformular o conteúdo de tal forma que ele se torne compreensivo aos alunos.

Este é também o conhecimento que se refere à compreensão docente do que facilita ou dificulta o aprendizado discente de um conteúdo em específico. Assim, o conhecimento do conteúdo pedagógico também inclui o entendimento do que torna fácil ou difícil a aprendizagem de determinado tópico, bem como as concepções errôneas dos estudantes e suas implicações na aprendizagem.

Argumentando que ensinar é antes de tudo entender, Shulman e seus associados consideram o pedagogical knowledge matter um conjunto de formas alternativas de representação que encontram origem tanto na pesquisa como nos saberes oriundos da prática docente. 0 knowledge base vai, além do conhecimento da disciplina por si mesma, para uma dimensão do conhecimento da disciplina para o ensino. Para o autor, a chave para distinguir a base do conhecimento do ensino repousa na interseção de conteúdos e pedagogia, na capacidade que um professor tem de transformar o conhecimento do conteúdo que ele possui em formas que sejam pedagogicamente eficazes e possíveis de adaptação às variações de habilidade e contexto apresentados pelos alunos.

O curricular knowledge dispõe-se a conhecer a entidade currículo como o conjunto de programas elaborados para o ensino de assuntos e tópicos específicos em um dado nível, bem como a variedade de materiais instrucionais disponíveis relacionados àqueles programas.

$\mathrm{Na}$ busca de melhor correlação para explicar o curricular knowledge, Shulman sugere a analogia: os professores precisam dominar o conhecimento curricular para poder ensinar aos seus alunos, da mesma forma que um médico precisa conhecer os remédios disponíveis para poder receitar.

A interdisciplinaridade curricular como atribuição profissional dos professores também é evidenciada por Shulman. Nesse caso, o autor destaca a habilidade do professor em relacionar o conteúdo de um dado curso ou lição

2. 0 professor "precisa entender não somente que algo é assim, mas também por que é assim, bem como em que pressupostos pode ele obter garantias e sob quais circunstâncias nossa crença na justificação (desses pressupostos) pode ser enfraquecida ou até mesmo negada. Além disso, nós esperamos que o professor entenda porque um dado tópico é particularmente central para uma disciplina enquanto que um outro qualquer possa ser periférico". (Tradução livre) 
em tópicos ou assuntos a serem discutidos simultaneamente em outras disciplinas.

Shulman (2004) apresenta uma concepção do ensino a partir das pesquisas realizadas com professores, com a intenção de entender como eles se tornam professores capazes de compreender a disciplina por si, elucidando-a de novas formas, reorganizando, promovendo atividades e emoções, utilizando metáforas, exercícios, exemplos e demonstrações, de modo que o conteúdo possa ser aprendido pelos alunos. Os estudos realizados permitiram entender que o ensino começa com um ato da razão, continua com um processo de raciocínio, culmina com o desempenho e, então, reflete-se mais sobre ele, até que todo o processo inicie novamente. Desse modo, o ensino é tido como compreensão e raciocínio, como transformação e reflexão. Trata-se de um processo de raciocínio pedagógico em que os professores aprendem a pensar pedagogicamente sobre o conteúdo da disciplina.

Feita a apresentação das concepções e tipologias acerca do saber docente a partir de Gauthier, Tardif e Shulman, finalizaremos esta primeira parte do texto buscando estabelecer algumas relações e considerações referentes a esses autores, apesar das diferenças de concepções e tipologias. Como podemos observar no Quadro 1, eles se dedicam a investigar a mobilização dos saberes nas ações dos professores e compreendem os educadores como sujeitos que possuem uma história de vida pessoal e profissional e que,

Quadro 1: Classificaçôes tipológicas e particularidades das pesquisas de Gauthier, Tardif e Shulman.

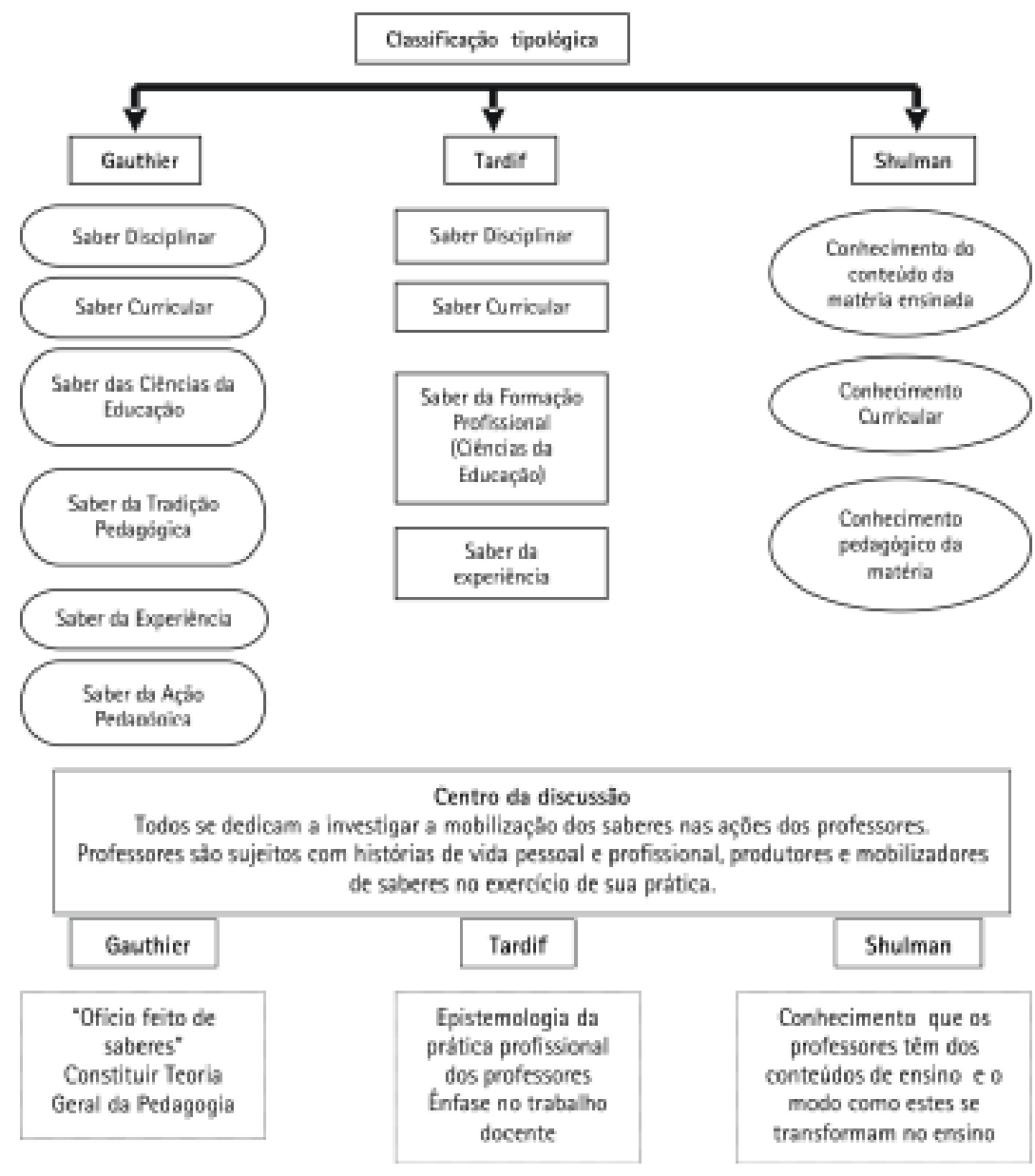


portanto, são produtores e mobilizadores de saberes no exercício de sua prática.

Do ponto de vista tipológico, apresentam classificações diferentes, porém não tão singulares a ponto de serem excludentes. As peculiaridades estão localizadas nos interesses investigativos. Gauthier (1998), ao defender um ofício feito de saberes, implementa esforços para a constituição de uma Teoria Geral da Pedagogia. Borges (2001) esclarece que uma das particularidades dos estudos de Gauthier e colaboradores é que exploram a literatura internacional sobre o tema, buscando definir a pedagogia ${ }^{3}$ e apresentar-lhe um modelo de análise. E ainda,

[...] traçam um panorama da evolução das pesquisas, sobre a eficácia no ensino, visando extrair elementos que possam contribuir para a edificação de um repertório de saberes. (p. 70)

Já os estudos de Tardif (2002) têm como particularidade o reconhecimento da pluralidade e heterogeneidade do saber, com destaque para os saberes da experiência que

\section{[...] surgem como núcleo vital do saber do-} cente, núcleo a partir do qual os professores tentam transformar suas relações de exterioridade com os saberes em relações de interioridade com sua própria prática. Neste sentido, os saberes experienciais não são saberes como os demais; são, ao contrário, formados de todos os demais, mas retraduzidos, "polidos" e submetidos às certezas construídas na prática e na experiência. (p. 54)

É nessa perspectiva que esses autores defendem a idéia de uma epistemologia da prática com a finalidade de revelar os saberes docentes,

[...] compreender como são integrados concretamente nas tarefas dos profissionais e como estes os incorporam, produzem, utilizam, aplicam e transformam em função dos limites e dos recursos inerentes às suas atividades de trabalho. (Tardif, 2002, p. 256)

A particularidade de Shulman (1986) reside no interesse em investigar o conhecimento que os professores têm dos conteúdos de ensino e o modo como estes se transformam no ensino. 0 autor e seus colaboradores têm por interesse esclarecer a compreensão cognitiva dos conteúdos das matérias ensinadas e das relações entre esses conteúdos e o ensino propriamente dito que os docentes fornecem aos alunos.

Os estudos de Borges (2001), de natureza pedagógica, consolidam a corrente do knowledge base

[...] numa perspectiva compreensiva da cognição e das ações dos docentes quanto ao desenvolvimento de projetos, atividades, teorias implícitas e explícitas que eles utilizam em seu trabalho, concepções sobre a matéria ensinada, currículo e programa etc. (p. 66)

$\mathrm{Na}$ conclusão desta primeira parte do texto, anuncia-se que, preservando as particularidades e singularidades de cada autor estudado, foi possível identificar similaridades e pontos de intersecção nas relações entre saberes docentes e formação inicial de professores, os quais serão apresentados a seguir.

\section{Implicações dos saberes para a formação docente}

Para analisarmos as implicações das pesquisas a respeito dos saberes docentes para formação inicial de professores no contexto das reformas, é necessário esclarecer que o movimento de reformulação dos cursos de formação tem sua origem nas críticas aos pressupostos do modelo da racionalidade técnica, que definem um determinado perfil de educador, bem como suas competências para ensinar. Nessa perspec-

3. Os autores preferem utilizar o termo Pedagogia em vez do termo Ensino, pois entendem que o primeiro envolve as duas dimensões fundamentais do ensino: 0 ensino dos conteúdos e a gestão da classe. 
tiva, a teoria é compreendida como um conjunto de princípios gerais e conhecimentos científicos, e a prática como a aplicação da teoria e técnicas científicas. Com base nesse pressuposto, os cursos de formação foram divididos em duas partes: na primeira, ensinavam-se as teorias e técnicas de ensino que eram apresentadas como saberes científicos e, portanto, inquestionáveis e universais; na segunda, os futuros professores realizavam, numa prática real ou simulada, a aplicação dessas teorias e técnicas.

Esse modelo de formação foi muito discutido e criticado, especialmente na década de 1990, por apresentar limitações como percurso formativo. No movimento de oposição a esse modelo, destacam-se as premissas defendidas pelo modelo da racionalidade prática. Esse modelo tem início com Donald Schön que, a partir de observações da prática de profissionais e tendo como suporte teórico a filosofia, especialmente influenciado por Dewey, propõe a superação da formação nos moldes de um currículo normativo e de caráter técnico-profissional. Schön (1995) acredita que essa formação impede o professor de dar respostas a si- tuações inéditas em sua prática, uma vez que não contará com conhecimentos elaborados pela ciência, o que dificultará ou até impossibilitará a aplicação de uma solução técnica.

Essa concepção de formação de professores foi amplamente divulgada nos últimos dez anos e dela decorreu uma vasta produção na área. Tal qual salientado por Sztajn (2002), autores que começaram suas trajetórias de pesquisa debruçando-se sobre os saberes docentes acabaram por circunscrever seus estudos no âmbito da formação docente, e com Gauthier, Tardif e Shulman não poderia ter sido diferente.

As concepções e tipologias acerca dos saberes docentes permitem destacar alguns pressupostos de caráter teórico e metodológico que têm influenciado o pensar e o fazer na formação inicial de professores tanto na América do Norte como na Europa e na América Latina.

$\mathrm{Na}$ tentativa de apresentar os indícios de alternativas de natureza teórica e prática para a formação inicial de professores, com base nas concepções e tipologias de Gauthier, Tardif e Shulman, elaboramos um mapa conceitual (Quadro 2) que demonstra algumas das impli-

Quadro 2: Implicaçōes das pesquisas sobre o Konwledge base para as propostas de formaçåo inicial

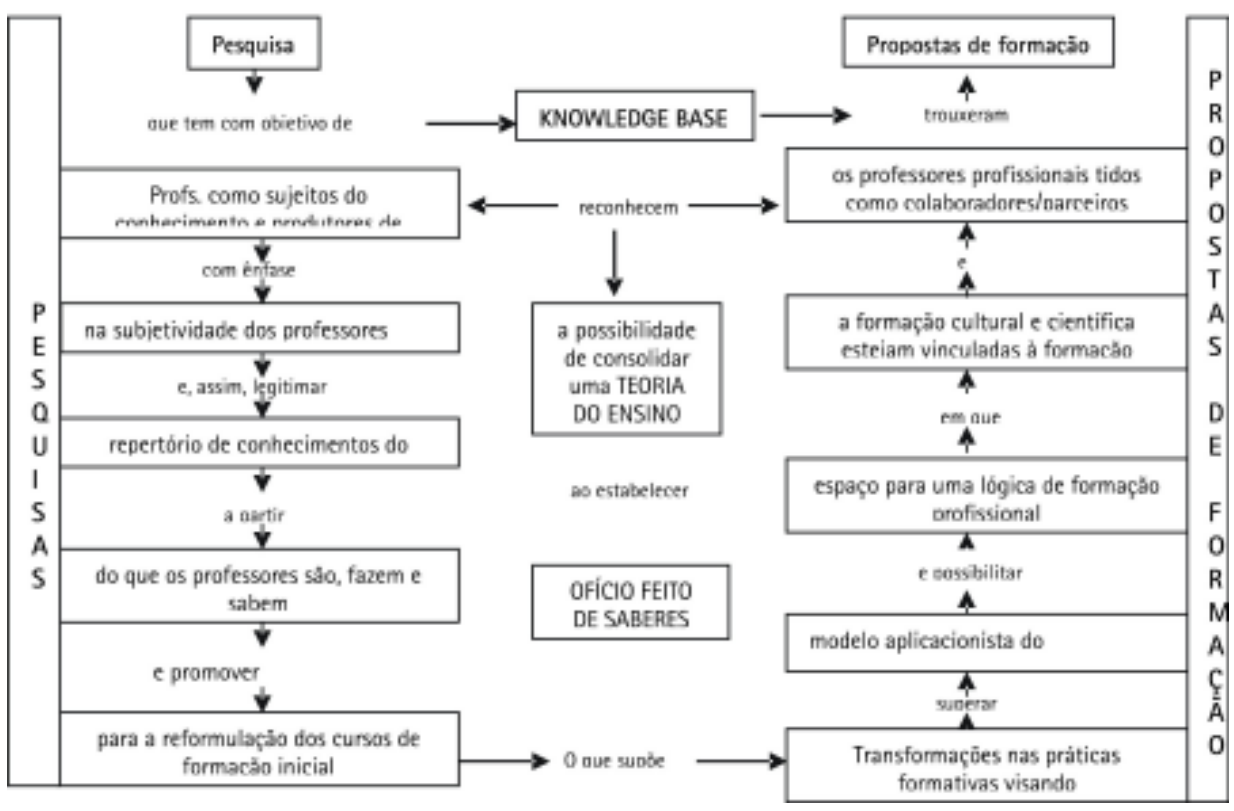


cações das pesquisas sobre o knowledge base para as propostas de formação inicial.

Como podemos observar, o mapa conceitual revela que as pesquisas acerca dos saberes mobilizados pelo professor na ação docente são suscetíveis de modificar nossas concepções em relação à formação profissional no magistério.

Reconhecer os professores como sujeitos do conhecimento e produtores de saberes, valorizando a sua subjetividade e tentando legitimar um repertório de conhecimentos sobre o ensino a partir do que os professores são, fazem e sabem constitui as bases para a elaboração de programas de formação.

Tardif (2002) explica que a atividade profissional dos professores de profissão deve ser considerada como um espaço prático de produção, de transformação e de mobilização de saberes e, conseqüentemente, de teorias, de conhecimentos e de saber-fazer específicos ao ofício de professor. 0 autor propõe um repensar das relações entre teoria e prática, pois entende que tanto a universidade como os professores de profissão são portadores e produtores de saberes, de teorias e de ações. Ambos comprometem seus atores, seus conhecimentos e suas subjetividades. Portanto, a

\section{[...] relação entre a pesquisa universitária e} o trabalho docente nunca é uma relação entre uma teoria e uma prática, mas uma relação entre atores, entre sujeitos cuja prática são portadoras de saberes. (p. 237)

A necessidade de transformação nas práticas formativas e superação do modelo baseado na racionalidade técnica é aclamada por todos os pesquisadores que tomam como objeto de estudo o ensino. Tardif (2002) argumenta que o modelo baseado na racionalidade técnica apresenta dois problemas epistemológicos: primeiro, por ser idealizado de acordo com uma lógica disciplinar e não conforme uma lógica profissional centrada no estudo das tarefas e realidade do trabalho dos professores; e segundo, por tratar os alunos como espíritos virgens, não levando em consideração suas crenças e representações anteriores a respeito do ensino. É nessa perspectiva que as transformações nas práticas formativas implicam superar 0 modelo aplicacionista do conhecimento e elevar o nível de conhecimento dos professores, tendo em vista o repertório de saberes sobre o ensino.

A superação desse modelo aplicacionista supõe valorizar o conhecimento dos professores profissionais e reconhecê-los como colaboradores e parceiros nas práticas formativas.

Marcelo Garcia (1999), ao analisar o currículo de formação inicial de professores, descreve estudos e tendências na área que corroboram para uma lógica de formação profissional em que os saberes transmitidos pelas instituições de formação sejam concebidos e adquiridos em estreita relação com a prática profissional dos professores nas escolas. Parece ser consenso que a formação inicial deve possibilitar um saber-fazer prático racional e fundamentado para agir em situações complexas de ensino. Assim, o conhecimento-base deve constituir-se a partir de vivências e análise de práticas concretas que permitam constante dialética entre a prática profissional e a formação teórica e, ainda, entre a experiência concreta nas salas de aula e a pesquisa, entre os professores e os formadores universitários.

Para Tardif (2002), a formação inicial visa habituar os alunos, futuros professores, à prática profissional dos professores de profissão e fazer deles práticos reflexivos.

0 ideário de Shulman também converge nessa direção. Ao estabelecer importantes paralelos e contrastes entre as diversas profissões, põe em relevo o papel basilar do learning from experience (aprendizado a partir da experiência) como componente fundamental do constructo de saberes constituintes de uma profissão. No ensino, não poderia ser diferente. Para o autor, o aprendizado a partir da prática é a melhor descrição do que se poderia denominar de aprendizado para ensinar, pois é por meio dele que se tem a oportunidade de aprender a lidar com a surpresa, a incerteza e a complexidade intrínsecas ao microcosmo do cotidiano da sala de aula. 
No entanto, para que um aprendizado do tipo learning from experience possa ser validado como tal em instâncias de formação docente, é necessário que seja construído um repertório de experiências no formato do que Shulman denominou de artifact of scholarship ${ }^{4}$.

Segundo o autor, o artifact of scholarship seria um arcabouço de experiências, vivências, casos, erros, acertos e estratégias cujo contato com o seu repertório propiciaria aos professores incipientes o aprendizado a partir da prática de outros professores que já trilharam os seus primeiros passos e que estão, ou já estiveram, em pleno exercício profissional. Para ele, a imensa maioria das profissões já possui seus artifacts of scholarship definidos de longa data. Nós, profissionais da Educação, é que ainda estamos engatinhando no processo de construção de nossos artefatos.

É por esse motivo que o autor nos convida a olhar para a prática de nossos pares através das janelas de suas salas de aula, a fim de ver o que estão a fazer e a aprender de suas próprias práticas. Isso significaria abandonarmos a individualidade intrínseca de nossa profissão e estarmos abertos para aprender uns com os outros. Isso porque, para vermos, precisamos estar preparados para sermos vistos.

Nessa perspectiva, é preciso que os cursos de formação inicial em parceria com os professores de profissão promovam novas práticas e novos instrumentos de formação, como estudos de caso e práticas, estágios de longa duração, memória profissional, análise reflexiva, problematizações etc. Para Tardif (2002), esse movimento provoca o surgimento de novos atores situados na interface entre a formação e a profissão: professores associados, responsáveis pelos estágios, mentores, tutores etc.

\section{Concluindo}

Analisar as produções referentes ao saberes docentes, mesmo que partindo de perspectivas conceituais e tipológicas diferentes, permitiu a constatação de que é preciso garantir que as formações cultural, científica, peda- gógica e disciplinar estejam vinculadas à formação prática, consolidando, assim, uma Teoria do Ensino que supere os obstáculos que se interpuseram à pedagogia: de um ofício sem saberes e de saberes sem ofício.

A elaboração de um repertório de conhecimentos para o ensino, tendo como referência o knowledge base, ou seja, os saberes profissionais dos professores, tais como estes os mobilizam e utilizam em diversos contextos do trabalho cotidiano, é fundamental para introdução de dispositivos de formação que visem habituar os futuros professores à prática profissional. Não obstante, as reformas nos cursos de formação de professores iniciadas com esse propósito, na década de 1990, nos Estados Unidos e Canadá, apesar de expressivas, têm revelado alguns problemas e limitações.

Tardif (2002), ao fazer um balanço crítico a respeito dos resultados e dos problemas gerados pelas reformas, apresenta algumas dificuldades como aquelas decorrentes do insuficiente financiamento das reformas, das dificuldades de parceria entre as escolas e as universidades etc. Argumenta ainda que os cursos de formação de professores, na sua maioria, continuam organizados por formas tradicionais de ensino e por lógicas disciplinares e não por lógicas profissionais.

Apesar dos problemas enfrentados pelas reformas, o autor menciona que elas caminham numa boa direção e que é possível identificar iniciativas muito positivas ao revelar que a formação de professores tornou-se, nas universidades, assunto-chave nas pautas. Observa-se que as autoridades têm reconhecido sua crescente importância ao incentivar a promoção qualitativa das políticas, das instâncias e dos programas de formação.

Ainda que pesem as dificuldades de relação entre as universidades e as escolas, o balanço crítico demonstra que as parcerias entre ambas as instâncias se multiplicaram e se estabilizaram, com muitos casos de sucesso. 0

4. Artefato de sabedoria, escolaridade, escolástico. A tradução desse termo permite várias interpretações. 
mesmo se estende à pesquisa sobre o ensino: os progressos são inegáveis.

Considerando as possibilidades e limitações dos movimentos das reformas nos cursos de formação de professores, há esperança de que, no Brasil, os centros formativos façam dessa ocasião um momento de conquistas e avanços nas práticas formativas e na profissionalização docente.

Observa-se que os campos de pesquisa sobre o pensamento do professor influenciaram de forma marcante a constituição das atuais Diretrizes Curriculares Nacionais para a Formação de Professores da Educação Básica em nível superior, aprovada em 08/05/2001 e regulamentada na resolução $n^{\circ}$ 01, de 18 de fevereiro de 2002, do Conselho Nacional de Educação. Faz-se necessário advertir que, mesmo diante de um quadro tão frutífero de produções acadêmicas e cientificas com conseqüente perspectivas de superação do modelo da racionalidade técnica, os princípios norteadores das Diretrizes Curriculares têm despertado interpretações e tratamento que preocupam o meio acadêmico atento às interfaces do neoliberalismo e do pós-modernismo nas políti- cas educacionais, em especial nas que se referem à formação de professores.

Sem dúvida, faz-se necessário uma reflexão crítica acerca das reformas, no entanto sem se limitar às restrições e ambigüidades das reformas. É preciso também analisar e viabilizar as possibilidades de ações e avanços nas práticas formativas. Concordamos com Macedo (2003) quando diz que

maximizar a importância dos mecanismos de controle acaba por dificultar que sejam percebidos e eventualmente utilizados os espaços cotidianos de resistência. (p. 40)

Desse modo, as universidades e os centros universitários têm responsabilidade social com a formação de professores e com a educação do nosso país. E mesmo em contextos adversos, é possível construir práticas de formação inicial e continuada comprometidas com um ensino de qualidade, que não perca de vista a dimensão ética e política, bem como as discussões e reflexões sobre os fins da educação.

\section{Referências bibliográficas}

BORGES, C. Saberes docentes: diferentes tipologias e classificações de um campo de pesquisa. Educação \& Sociedade. Dossiê: Os saberes dos docentes e sua formação. Campinas: Cedes, n. 74, Ano XXII, p. 11-26, abr., 2001.

BORGES, C.; TARDIF, M. Apresentação. Educação \& Sociedade. Dossiê: Os saberes dos docentes e sua formação. Campinas: Cedes, n. 74, Ano XXII, p. 11-26, abr., 2001.

BRASIL. Conselho Nacional de Educação. Ministério da Educação. Diretrizes Curriculares Nacionais para a Formação de Professores da Educação Básica, em nível superior, curso de licenciatura, de graduação plena. Parecer n. 009, de 08 de maio de 2001.

Resolução n. 1, de 18 de fevereiro de 2002.

GAUTHIER, C. Por uma teoria da Pedagogia: pesquisas contemporâneas sobre o saber docente. Ijuí: Unijuí, 1998.

MACEDO, E. Identidade profissional e diretrizes curriculares de formação de professores da educação básica. In: ENDIPE. (Org.). Políticas Educacionais, práticas escolares e alternativas de inclusão escolar. v. 1. Rio de Janeiro: DP\&A, 2003.

MARCELO GARCIA, C. Formação de professores: para uma mudança educativa. Portugal: Porto, 1999.

SCHÖN, D. Formar professores como profissionais reflexivos. In: NÓVOA, A. (Org.). Os professores e sua formação. 2 ed. Lisboa: Dom Quixote, 1995 
SHULMAN, L. S. Those who understand: knowledge growth in teaching. Educational, v. 15, n. 2, p. 4-14, 1986.

The wisdom of practice: essays on teaching and learning to teach. San Francisco: Jossey-Bass, 2004.

SZTAJN, P. 0 que precisa saber um professor de matemática? Uma revisão da literatura americana dos anos 90. Educação Matemática em Revista. SBEM, ano 9, n. 11 A, 2002 (p.17-28).

TARDIF, M. Saberes docentes e formação profissional. Petrópolis: Vozes, 2002.

TARDIF, M.; LESSARD, C. 0 trabalho docente: elementos para uma teoria da docência como profissão de interações humanas. Petrópolis: Vozes, 2005.

TARDIF, M.; LESSARD, C.; LAHAYE, L. Esboço de uma problemática do saber docente. Teoria \& Educação. v. 1, n. 4, p. 215-253, 1991.

TARDIF, M.; LESSARD, C.; GAUTHIER, C. Formação dos professores e contextos sociais. Porto: Rés, 2001.

Recebido em 24.08.06

Aprovado em 27.04.07

Patrícia Cristina Albieri de Almeida, mestre e doutora em Educação pela Universidade Estadual de Campinas, desenvolve atividades de pós-doutorado na Pontifícia Universidade Católica de São Paulo.

Jefferson Biajone, mestre em Educação na área de Educação Matemática pela Universidade Estadual de Campinas, é professor de Matemática da Escola Preparatória de Cadetes do Exército. E-mail: aspbiajone@espcex.ensino.eb.br. 